\title{
The Transforming Face of Fracture Epidemiology
}

\author{
Babak Haghpanah ${ }^{1, *}$ \\ ${ }^{1}$ Trauma Research Center, Kashan University of Medical Sciences, Kashan, IR Iran \\ *Corresponding author: Babak Haghpanah, Trauma Research Center, Kashan University of Medical Sciences, Kashan, IR Iran. Tel: +98-3615550026, E-mail: babakhp@gmail.com
}

Received: September 7, 2014; Accepted: September 7, 2014

Keywords: Epidemiology; Trauma

Skeletal trauma has been influencing the productive life of population, especially in more developed urban areas. During the past few years, most skeletal trauma registries throughout the world have been reporting an increase in incidence and a change in pattern of fractures $(1,2)$. The most prevalent cause of skeletal fracture in younger population is road traffic accident. Although the development of modern passenger restraint systems has led to decreased mortalities from cerebral and spine trauma, it may have indirectly been increasing the nonfatal patterns of skeletal fractures, which includes the fractures induced by the restraint system itself $(3,4)$. Older people have traditionally been suffering from lowenergy traumas like falling. Modernization of the society, shifting age distribution of the population, changing life style, and alteration in the attitude and culture of different age groups have influenced the pattern of epidemiology of skeletal trauma.

With the increasing pace of modern life, high-energy traumas are seen more frequently and in the age groups that were traditionally not "high-energy type of people", e.g. children and the elderly. Women and children are more frequently participating high-energy athletic and recreational activities. One of the most pronounced alterations in fracture epidemiology has been seen in higheraged females. The increase in the prevalence of fractures in elderly women, reported in some databases, is partly due to the increase in overall population age and partly because of the changing in the activity level of this age group -they may suffer from the fractures that were once specific to the younger population.

Apart from the high-energy accidents, the fractures caused by the most common metabolic disease of the bone, the osteoporosis, are rising and imposing an increasing burden on both the individual and society. A study by Cauley et al. (5) showed that the projected num- ber of women who will experience a fracture in one year, exceeded the combined number of women who would experience invasive breast cancer or a broad category of cardiovascular events. Such an increase in incidence and burden has been reported in some studies in our own country $(6,7)$. On the other hand, some studies show that the majority of orthopedic surgeons lack sufficient training in management of osteoporosis in our country (8).

Iran is a large country with an exceptional climatic, cultural and ethnic diversity. Knowledge of patterns of skeletal injuries and their epidemiology will undoubtedly improve prevention and care of such patients and plays a major role in decreasing burden on the growing economy. Such a goal will not be reachable except on a background of a nationwide orthopedic trauma registry system.

\section{References}

1. Court-Brown CM, Biant L, Bugler KE, McQueen MM. Changing epidemiology of adult fractures in Scotland. Scott Med J. 2014;59(1):30-4.

2. Court-Brown CM, Caesar B. Epidemiology of adult fractures: A review. Injury. 2006;37(8):691-7.

3. Blacksin MF. Patterns of fracture after air bag deployment. J Trauma.1993;35(6):840-3.

4. Estrada LS, Alonso JE, McGwin G, Jr, Metzger J, Rue LW, 3rd. Restraint use and lower extremity fractures in frontal motor vehicle collisions. J Trauma. 2004;57(2):323-8.

5. Cauley JA, Wampler NS, Barnhart JM, Wu L, Allison M, Chen Z, et al. Incidence of fractures compared to cardiovascular disease and breast cancer: the Women's Health Initiative Observational Study. Osteoporos Int. 2008;19(12):1717-23.

6. Maharlouei N, Khodayari M, Forouzan F, Rezaianzadeh A, Lankarani KB. The incidence rate of hip fracture in Shiraz, Iran during 2008-2010. Arch Osteoporos. 2014;9:165.

7. Ahmadi-Abhari S, Moayyeri A, Abolhassani F. Burden of hip fracture in Iran. Calcif Tissue Int. 2007;80(3):147-53.

8. Mehrpour SR, Aghamirsalim MR, Sorbi R. Are hospitalized patients with fragile fractures managed properly in relation to underlying osteoporosis? J Clin Rheumatol. 2012;18(3):122-4. 